\title{
Ethical conflict in the practice of occupational medicine
}

\author{
P W BRANDT-RAUF \\ From the Columbia-Presbyterian Medical Center, New York, NY 10032, USA
}

\begin{abstract}
The practice of occupational medicine has been portrayed as being fraught with ethical conflict and yet this problem has received little systematic study. A question and case study survey of a randomly selected cohort of members of the American Occupational Medical Association has been performed to examine the extent and nature of this problem in occupational medicine practice in the United States. The results indicate a strong reliance on traditional medical role models in responding to ethical conflict but with significant underlying tension between more deontological physicianpatient approaches and more teleological public health approaches. These results have significant implications for the synthesis of bioethical theories based on a perceived complementarity of ethical reality, as well as suggesting important improvements in future occupational medicine training.
\end{abstract}

\begin{abstract}
Areas of ethical conflict inherent in the practice of occupational medicine have received increased attention in recent years. Issues such as confidentiality, the workers' right to know, individual autonomy versus paternalism, informed consent to risks, genetic screening, reproductive rights in the workplace, the double agent problem of occupational health professionals, cost benefit analysis in occupational health standard setting, equity and fairness in workers' compensation, and workers' responsibility to participate in research and the rights of notification of workers at high risk, among others, all arise when one considers the impact of the workplace on health..$^{1-8}$ Many reports suggest that ethical conflict for the occupational medicine practitioner has its roots in the diverse roles, loyalties, and responsibilities assumed by a physician in the occupational health setting. ${ }^{-15}$ The occupational physician has duties to himself, the patient, the employer, the government, society at large, labour, and the medical profession. Although many observers and practitioners have discussed these problems in an anecdotal or abstract theoretical manner, there has been no systematic attempt to study practitioners of occupational medicine to ascertain the true extent of these problems and how they are resolved in practice. This study is such an attempt based on a questionnaire survey of a sample of the members of the American Occupational Medical Association.
\end{abstract}

\section{Methods}

An approximate $5 \%$ sample (total $=218$ ) of the membership of the American Occupational Medical Association was selected for study from the membership directory by random number generation. A questionnaire was mailed to each of the individuals selected. Initial response on the first mailing was 59 $(27 \%)$. A second follow up mailing to non-responders three months later yielded an additional 21 responses. Thus the overall response rate was $37 \%$. In addition, eight $(10 \%)$ of the respondents were randomly selected for individual interviews, either in person or by telephone, to provide a more in-depth analysis of the answers provided on the questionnaire.

The questionnaire consisted of three parts: the personal characteristics of the respondent, a personal assessment of ethical conflict in the respondent's practice, and hypothetical case studies of ethical conflict in the practice of occupational medicine.

The first part included: age, sex, race, location and area of practice, training in terms of board eligibility and board certification, type of practice in terms of the proportion of occupational medicine involved (greater than $75 \%, 25-75 \%$, less than $25 \%$ ), and type of employee (full time employee of industry, part time employee of industry, government, university/research institute, independent/group practice, labour/ union), primary responsibility in the occupational medicine practice (patient care, administrative/managerial, research/teaching), and religious preference. 
The second part of the questionnaire required answers of Never, Rarely, Sometimes, Frequently, or Always to questions about ethical conflict in the respondent's practice of occupational medicine. These included: the frequency with which conflict arises; the frequency with which such conflicts involve responsibilities to and primary loyalty to oneself, the patient, management, other employees, government agencies, labour, society, and the medical profession; the frequency with which the subject of the conflict is confidentiality, dissemination of scientific findings, cost, acceptability of risk, disagreement with other health professionals, or refusal to treat; the frequency of reliance on various sources for resolution of conflicts such as codes of ethics, laws, religious beliefs, utilitarianism, intuition, or personal beliefs; and recommendations for future improvements in conflict resolution including codes of ethics, laws, changes in training, better role definition, and better role models.

Three cases were included. The first involves the medical evaluation of an employee who is thought by the physician to have an alcohol problem and is being considered for a promotion with three variations to this scenario. In one variant the physician is informed by coworkers that the individual's behaviour at work is endangering the health and safety of others. In the second variant coworkers have expressed their concern about the individual's ability to do his job but he represents no danger to others. In the third variant the individual's behaviour at work has not changed noticeably and his drinking has not affected his ability to do his current job, but management has specifically requested a comment from the physician on the employee's ability to take up his new, more stressful position. Choices of action for each variant are: inform management that the individual may not be able to perform his work due to a medical problem, inform management that the individual may not be able to perform his work due to an alcohol problem, do not inform management of any problem.

In the second case study the physican discovers a previously unreported association between working with a particular material and heart disease in his company's employees. The results are written up for publication and the paper is submitted for internal review. The company refuses to allow publication and gives one of four reasons: no reason, it exposes proprietary information, it will attract unwanted publicity, or it may leave the company open to litigation. For each reason given, choices of action open to the physician include: do nothing, amass more data to persuade management, informally inform colleagues, submit the paper anyway, leak the information to the press or government, or resign.

In the third case the physican in a small community also spends half the time working for a local company.
The company employs most of the workers in the community and the physician is also the private physician of many of the workers. Work at the company entails exposure to a particular hazardous compound for which the government is considering $\overrightarrow{\vec{g}}$ lowering the standard of exposure because of at association with chronic lung disease. Compliance with the new standard is expected to be quite costly butif. will prevent two deaths a year nationwide. There hav been no deaths attributable to exposure at this paro ticular company but there have probably been new of exacerbated cases of chronic lung disease. The new standard might be expected to reduce these and save one death at this company over the lifetime of thfo company physician, but the cost of compliance wi probably force the company out of business an\& considerably increase unemployment in the commun ity. The physician is asked to choose one of fou? options: support the standard because $(a)$ primar responsibility is to reduce any occupational disease af any cost, or $(b)$ responsibility for the physical health of these workers would outweigh any economic con $\vec{z}$ sequences; or oppose the standard because $(a)$ primary responsibility is the health and welfare of thes workers and that includes their economic well being? or $(b)$ economic consequences nationwide exceed the benefits in workers' health.

In addition, for all questions and case studies क्fie respondents were provided with the opportunity supply any additional comments about their respons ses. In the analysis of responses an attempt was made to correlate answers on the second and third parts of the questionnaire with the particular characteristics of the respondents provided on the first part of th $\overrightarrow{\vec{E}}$ questionnaire and between responses to the case studies on the third part and answers provided to thei personal experience on the second part of the ques:tionnaire. Furthermore, an effort was made to ascerp tain any differences between respondents and non 3 respondents in terms of personal characteristics by checking the non-respondents in other reference lis? ings of physicians; based on these estimates, nons respondents did not appear to differ significantly from respondents in terms of age, sex, or location of practice.

\section{Results}

The summary of personal characteristics of resporn dents is as follows: average age 52 (range 33-76); 96\% male, $4 \%$ female; $89 \%$ Caucasian, $4 \%$ black, $3 \%$ Hispanic, $4 \%$ Oriental; $60 \%$ practiced in an urbâ area, $31 \%$ in a suburban area, and $9 \%$ in a rural aree and most respondents were from states in the northe east, middle Atlantic, or west coast regions; $35 \%$ of respondents were not board certified in any specialt $\bar{\Phi}$ 
although $36 \%$ of these were board eligible in occupational medicine, $21 \%$ were board eligible in internal medicine, and $7 \%$ in some other specialty; $65 \%$ of respondents were board certified $(48 \%$ in occupational medicine, $32 \%$ in internal medicine, and the remainder in other specialties) and $15 \%$ of these were board certified in two specialties (usually internal medicine and occupational medicine); $73 \%$ spent more than $75 \%$ of their time in occupational medicine, $13 \%$ spent $25-75 \%$ of their time in occupational medicine, and $14 \%$ spent less than $25 \%$ of their time in occupational medicine; $55 \%$ were full time employees of industry, $13 \%$ were part time employees of industry, $1 \%$ worked for government, $5 \%$ worked for a university or research group, and $26 \%$ were in independent or group practices; $54 \%$ were engaged in patient care, $40 \%$ in administration, and $6 \%$ in teaching or research; $58 \%$ were Protestant, $18 \%$ were Roman Catholic, $14 \%$ were Jewish, and $9 \%$ listed no religious preference.

Sixty nine per cent of respondents thought ethical conflicts arose sometimes $(48 \%)$, frequently $(18 \%)$, or always $(3 \%)$ in their practices; $31 \%$ responded rarely and no one responded never. Problems that did arise involved conflicting responsibilities to themselves, the patient, and management most often (in each case greater than $60 \%$ of responses were in the sometimes, frequently, or always categories). Although in many cases, primary loyalty was thought to be to themselves (30\% sometimes, $13 \%$ frequently, $25 \%$ always) or to management (38\% sometimes, $28 \%$ frequently, $2 \%$ always), the overriding primary loyalty was clearly to the patient $(19 \%$ sometimes, $25 \%$ frequently, $56 \%$ always). Conflicts frequently involved confidentiality (40\% sometimes, $18 \%$ frequently, $9 \%$ always), cost ( $25 \%$ sometimes, $23 \%$ frequently, $2 \%$ always), and acceptability of risk ( $44 \%$ sometimes, $15 \%$ frequently, $2 \%$ always). In resolving conflicts respondents reported professional codes of ethics (20\% sometimes, $33 \%$ frequently, $22 \%$ always) and personal beliefs (34\% sometimes, $25 \%$ frequently, $16 \%$ always) to be most useful; in addition, five individuals $(6 \%)$ wrote in responses for company guidelines as being useful in these circumstances. Recommendations for future change favoured better role definition $(29 \%$ sometimes, $40 \%$ frequently, $16 \%$ always), better role models $(29 \%$ sometimes, $33 \%$ frequently, $17 \%$ always), changes in training (31\% sometimes, $33 \%$ frequently, $11 \%$ always), and more codes of ethics ( $23 \%$ sometimes, $15 \%$ frequently, $10 \%$ always).

Responses to the case studies varied. In the case of the alcohol abuser where he may be endangering others most respondents $(67.5 \%)$ would inform management of a medical problem and many $(22.5 \%)$ would inform management specifically of an alcohol problem. This changed slightly if the employee were no danger to others with $49 \%$ reporting a medical problem and $25 \%$ reporting an alcohol problem. In terms of responding to the employee's ability to assume a new job, $41 \%$ would inform of a medical problem, $19 \%$ of an alcohol problem, but $40 \%$ would not indicate any problem to management.

For the case involving dissemination of scientific information, the responses did not vary significantly with the reason given by the company for denying permission. In all cases at least $70 \%$ of individuals responded that they would attempt to amass more data to persuade management. Less than $5 \%$ of respondents would do nothing. Approximately $10 \%$ would inform colleagues informally and $5 \%$ each would submit the paper anyway, leak the information to the press or government, or resign.

In the case of the new standard about half the respondents would support the standard and half would oppose it ( $51 \% v 49 \%$, respectively). Of those supporting the standard, $66 \%$ thought that their responsibility for the physical health of the workers would outweigh any economic consequences and $34 \%$ thought their primary responsibility was to reduce all occupational disease. Of those opposing the standard, $67 \%$ thought their primary responsibility to their patients included their economic well being and 33\% thought that economic consequences nationwide exceeded the benefits to workers' health in general.

Unfortunately, owing to the small numbers concerned, no significant associations were found between responses on the three parts of the questionnaire.

\section{Discussion}

Despite the lack of specific associations observed between responses on this questionnaire survey, several important observations may be made. Firstly, assuming that respondents are an accurate reflection of occupational medicine practitioners in the United States in general, it would seem that ethical conflicts are perceived as a relatively frequent occurrence in practice and, not surprisingly, that they frequently involve conflicting feelings of loyalty or responsibility toward the patient, management, and the practitioner. Most respondents, however, in dealing with these conflicts relied on the traditional medical model of their education and training in that their primary loyalty, duty, or responsibility was thought to be to the patient - that is, regardless of their perceived role in practice (patient care versus administration versus research), their basic response to these problems was as a physician.

The actual mechanics of this decision making process among respondents, however, were less clear. The strong reliance on professional codes of ethics that was indicated by respondents may be as much a 
reflection of their basis in the traditional physician model with primary responsibility to the patient as their content of any specific guidelines for dealing with particular problems. The responses and written and verbal comments to the case studies, particularly the case dealing with standard setting, showed a real tension in the mechanics of analysis between the role of the occupational medicine professional as a physician in a doctor-patient relationship and as a public health official with responsibilities to larger groups (the company, the community, the nation), roles that may obviously conflict. Comments regarding an "absolute duty to the patient" that were juxtaposed to a regard for the "general welfare" put into clear relief the difference between a traditional deontological approach and a teleological utilitarian approach. Perhaps rightly so, what was conveyed by these comments was a perceived complementarity of ethical reality in many occupational health dilemmas as, for example, there is a perceived complementarity of physical reality in dealing with certain scientific areas such as particle physics. Thus just as an electron beam may be rightly judged to be a particle form or a wave form depending on the measurement approach taken, so the ethics of a situation may be rightly judged to be deontological or teleological (or of some other ethical theory) depending on the analytical approach taken. In both cases the realities judged are equally valid, mutually exclusive, complementary aspects of some overriding total reality that can only be rationally approached by the deconstruction inherent in the methods of analysis. Furthermore, just as the physicist, to have the best understanding of this total reality for subatomic particles, must be conversant with both methods of analysis, it would seem logical that the physician should be conversant with relevant ethical theories of analysis in order to achieve the best understanding of the total ethical reality in situations of conflict. This seemed to be precisely the point on which respondents to the questionnaire were floundering; they could not put their vaguely perceived complementarity of the situation within theoretical frameworks of analysis.

One major conclusion that may be drawn from this discussion is the need for more teaching of ethics in occupational medical training. Professionals who have not received any formal training in occupational medicine (and this is obviously a considerable proportion based on our respondents of whom $22 \%$ were not even board eligible in occupational medicine) are at an obvious disadvantage in this respect, never having had the opportunity to consider such problems under supervision before having to deal with them in practice. It seems likely, however, that even formal training programmes are not perceived as devoting sufficient time to this area. This conclusion is supported by respondents' replies concerning future improvements in resolving conflicts. For example, whereas respon dents indicated a heavy reliance on professional codês of ethics for solving current problems, their response to the need for more or better codes in the future was much less definitive. Rather, they expressed an intere in better role models in training and other changes if training (including specific mention of more discussiog of ethics in training, in several cases) as needects improvements for the future. At our institution, have approached this problem by explicitly including ethics in the occupational medicine curriculum. Fôr example, for the past five years we have offered a fut semester course in occupational health ethics, whict deals with the basics of ethical theories and theyse application to the workplace, as well as selected lectures in other courses such as ethics in occupation medicine management and ethics in occupationad medicine practice. Based on the results of this survey; would propose that all training programmes occupational medicine carefully examine theif curriculum to ensure adequate coverage of occupational health ethics so that occupationat medicine physicians of tomorrow will be as we prepared as possible to cope with the difficult and complex issues they will most certainly face in practice.

\section{References}

1 Brandt-Rauf PW, Brandt-Rauf SI. OSHA: fertility to feasibi就 Occup Health Saf 1979;48: 35-41.

2 Brandt-Rauf SI, Brandt-Rauf PW. Occupational health ethics OSHA and the courts. Journal of Health Politics, Policy an\& Law 1980;5:523-34.

3 Brandt-Rauf PW, Brandt-Rauf SI. Ethical aspects of reproductive health in the workplace. Occupational Medicine 1986;1:509-15욱

4 Brandt-Rauf SI, Brandt-Rauf PW. Workers' compensation and occupational cancer. Seminars in Occupational Medicin 1987;2:321-3.

5 Murray TH, Bayer R. Ethical issues in occupational health. In Humber JM, Almeder RF, eds. Biomedical ethics reviews Clifton,NJ: Humana Press, 1984:153-73.

6 Hunt VR. Perspective on ethical issues in occupational health. In Humber JM, Almeder RF, eds. Biomedical ethics reviews. Clifton,NJ: Humana Press, 1984:175-201.

7 Schulte PA, Ringen K. Notification of workers at high risk: a emerging public health problem. Am J Public Health 1984;74:485-91.

8 Conference on ethical issues in occupational medicine. Bull $N \vec{Y}$ Acad Med 1978;54:705-820.

9 Balk JL. Problems in providing medical care and economic redress. to injured workers: the physician's responsibility: ethical and legal considerations. Ann NY Acad Sci 1979;330:513-20.

10 Carrick D. Loyalties of a company doctor. J Soc Occup MeßN 1977;27:72-3.

11 Goldsmith J. The new ethic: the doctor's responsibility for healt fN on the job. Environ Res 1976; 11:170-5.

12 Dinman BD. The loyalty of the occupational physician. Bull $N$ Acad Med 1978;54:729-32.

13 Whorton D, Davis M. Ethical conduct and the occupationat physician. Bull NY Acad Med 1978; 54:733-41.

14 Anonymous. Ethics in occupational medicine. Lancet 1980;ii:134

15 Anonymous. Occupational physicians and ethics. $\mathrm{Br} \mathrm{Med} \Phi$ 1981;282:90-1. 